\title{
Performance and Emission Analysis of CIDI Engine Fueled with Palm Biodiesel Blends and Nano Particles
}

\author{
Kavide Shekhar, Sirivella Vijaya Bhaskar
}

\begin{abstract}
The diesel fuel is most extensively used fossil fuel in automotives and a single major source of hazardous environment pollutant across the globe. As of late, the exploration thinks about distinguished that plant based biodiesel are turning into a promising option sustainable fuel and the consumable/non-eatable oils and creature fats can be utilized feed-stock in arrangement of biodiesel, in light of the fact that its chemical properties practically like fossil diesel fuel, non-poisonous, clean consuming and inexhaustible source. In this work, the performance analysis and emission characteristics of single cylinder, 4-stroke, and water cooled diesel engine was carried-out using Palm oil methyl ester as biodiesel alternative to diesel fuel. Experimental tests have been conducted with range of engine loads using palm oil methyl ester (PME) and its diesel blends with biodiesel in the ratio of 10:90 (B10), 20:80 (B20), and 30:70 (B30), 40:60 (B40), PME 100\% (B100) and petro-diesel $100 \%$ by volume with and without antimony tin oxide (ATO) additive. In this research work brake power (BP), brake thermal efficiency (BTE), brake specific fuel consumption (BSFC), fuel consumption (FC) are considered as engine performance characteristics and carbon monox ide (CO), hydro carbons (HC), oxides of nitrogen (NOx) are considered as emission characteristics. The experimental results revealed that B10 blend of biodiesel has comparable brake thermal efficiency as diesel. B10 has lowest and B100 has highest BSFC, FC among all the biodiesel blends and biodiesel has lower $\mathrm{CO}$ emission, lower $\mathrm{HC}$ emission and moderately higher NOx emission when compared with diesel. B10 has shown comparable performance as diesel and it can be considered as alternative to diesel fuel.
\end{abstract}

Keywords: Biodiesel, Performance, PME, Transesterification.

\section{INTRODUCTION}

Worldwide industrialization, population growth, and declining fuel reserves lead to search for alternative renewable fuels. Free unsaturated fat methyl esters referred to as biodiesel which is considered as option to petro-diesel is making progress as a bio-degradable, ecological neighborly, effectively accessible, vitality protection and the board. Biodiesel is a clean and renewable fuel which is made from natural elements such as plants, vegetables and reusable materials. The idea of utilizing vegetable oil as a engine fuel likely dates to when Rudolf Diesel (1858-1913) built up the main engine to keep running on shelled nut oil, as he showed at the World Exhibition in Paris in 1900.

\section{Revised Manuscript Received on December 30, 2019.}

* Correspondence Author

Kavide Shekhar, M. Tech. Scholar, Mechanical Dept., Sreenidhi Institute of Science and Technology, Yamnapet, Hyderabad (Telangana) India.

Sirivella Vijaya Bhaskar, Professor, Mechanical Dept., Sreenidhi Institute of Science and Technology, Yamnapet, Hyderabad (Telangana) India.

(c) The Authors. Published by Blue Eyes Intelligence Engineering and Sciences Publication (BEIESP). This is an open access article under the CC BY-NC-ND license (http://creativecommons.org/licenses/by-nc-nd/4.0/)
Rudolf Diesel immovably accepted the usage of a biomass fuel to be the genuine eventual fate of his engine. He needed to give ranchers the chance to deliver their very own fuel. In 1911 he said "The diesel engine can be sustained with vegetable oils and would help impressively in the advancement of agribusiness of the nations which use it". Sirivella vijaya bhaskar examined the performance analysis of direct injection (DI) diesel engine using jatropha curcas oil methyl (JCOME) as biodiesel and revealed that B20J biodiesel blend has comparable brake thermal efficiency to that of petro-diesel fuel and the lowest BSFC, BSEC with EGT in all tested biodiesel blends[1]. Syed Aalam et al., were conducted experiment in a CRDI diesel engine at a constant speed of $1500 \mathrm{rpm}$ using different ANP-blended biodiesel fuel (MME20 + ANP50 and MME20 + ANP100) and the outcomes were contrasted and those of perfect diesel and Mahua biodiesel mix (MME20) and uncovered that a significant upgrade in the BTE and a marginal reduction in the harmful pollutants (such as $\mathrm{CO}$, $\mathrm{HC}$ and smoke) for the nanoparticles blended biodiesel[2]. Ali M.A. Attia et al. were examined with alumina nano-particles are added to a mixture of jojoba methyl ester (biodiesel) and conventional diesel fuel at the most recommended value (20\% biodiesel and $80 \%$ diesel fuel) with different doses from 10 up to $50 \mathrm{mg} / \mathrm{l}$. It is found that, the appropriate nano-additives dose corresponding to optimal engine performance is about 30 $\mathrm{mg} / \mathrm{l}$. At this portion, the general BSFC is decreased by about $6 \%$, engine thermal efficiency is expanded up to $7 \%$, and all engine discharges have been diminished (NOx about 70\%, CO about $75 \%$, smoke opacity about 5\%, and UHC about 55 $\%)$ compared with the corresponding values obtained when only a blended fuel of $20 \%$ biodiesel is used[3]. Available literature reviews show that use of bio diesel lead to reduced engine power, increased BSFC because of reduction in heating values of biodiesel. But use of biodiesel has shown reduction in PM, HC and CO but increase of NOx emission. Vegetable oils are triglycerides of free unsaturated fats and liquor esters of unsaturated fats have been set up by the transesterification of the glycerides, wherein straight, monohydroxy alcohols responds with the vegetable oils within the sight of impetus to create liquor esters of vegetable oil. The liquor esters of vegetable oil when utilized as an elective diesel fuel have been distinguished as a biodiesel. Vegetable oils will have high consistency that messes major up in their utilization as powers in diesel motors, for example, warm splitting, oil ring staying and so forth. 
Further, it is hard to work CIDI motor in chilly climate conditions because of poor stream property of biodiesel. These issues can be settled, by artificially changing over the vegetable oils into biodiesel utilizing chemical procedures, for example, Micro emulsification, Pyrolysis, Dilution and Transesterification process. In this examination work, palm oil was changed over into biodiesel utilizing transesterification and mixed with diesel and antimony tin oxide additive was used.

\section{MATERIALS AND METHODS}

Palm oil was purchased from neighborhood merchant and utilized transesterification procedure to plan biodiesel. In the transesterification procedure, methanol was utilized in presence of catalyst for transesterification include sodium hydroxide, and potassium hydroxide. A triglyceride has an atom of glycerine as its base with three long chain unsaturated fats appended and fat attributes can be controlled by the idea of the unsaturated fats joined to the glycerine. The idea of the unsaturated fats can, thus, influence the qualities of the biodiesel. In this work methyl alcohol was utilized in transesterification process within the sight of sodium hydroxide was utilized. Transesterification is a compound procedure where an ester is responded with an alcohol to frame another ester and another alcohol. For the formation of biodiesel, triglyceride oils (esters) are responded with methanol (alcohol) to deliver biodiesel (unsaturated fat alkyl esters) and glycerin. As appeared in figure 1, in the chemical reaction of transesterification process $\mathrm{R} 1, \mathrm{R} 2$, and $\mathrm{R} 3$ are long hydrocarbon chains, regularly called unsaturated fat chains. There are just five chains that are basic in most vegetable oils and the five methyl esters decides the fuel's physical properties.<smiles>[R]C(=O)OCC(COC([R])=O)OC([R])=O</smiles>

Triglyceride

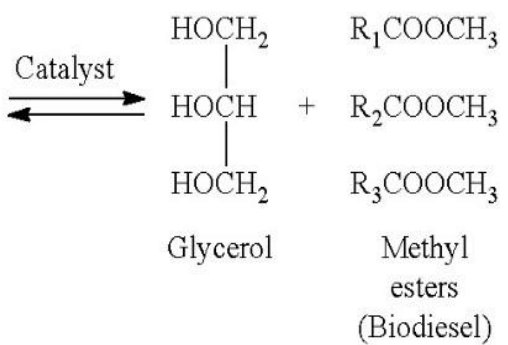

\section{Fig. 1. Chemical reaction of transesterification process}

As appeared in figure 2, sodium hydroxide takes an interest as catalyst and methyl alcohol as driver for the transesterification process. First palm oil of $1000 \mathrm{ml}$ was filled biodiesel reactor and afterward, the catalyst/alcohol blend was siphoned into palm oil. The last blend is mixed energetically for $2 \mathrm{hr}$ at $340 \mathrm{~K}$ in surrounding pressure.

A successful reaction results in 2 phases in the reactor and the bottom layer consisted of glycerine and top layer palm oil methyl ester. Glycerine, the heavier liquid will collect at the bottom after several hours of settling and then separated by using separation flask. Then the ester obtained is further treated with $25 \%$ water in two stages in order to remove any glycerin present in the ester and finally pure ester is obtained by heating the ester up to $100{ }^{\circ} \mathrm{C}$ to remove the water content completely.

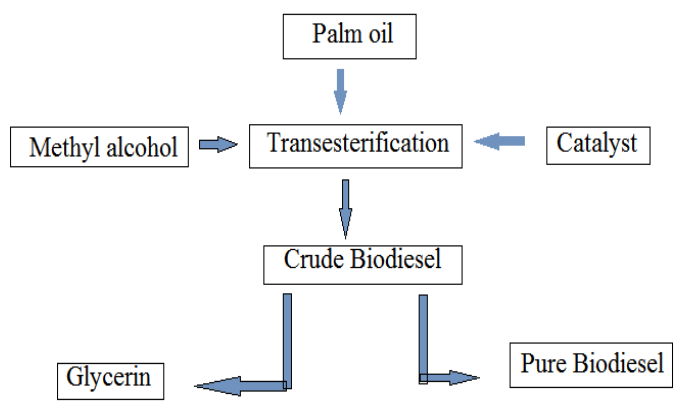

Fig. 2. Transesterification process flow

The properties of biodiesel rely upon molar proportion of alcohol to oil and numerous different variables and the palm oil methyl ester that was utilized in the present research work are displayed in Table 1.

Table-I: Properties of palm biodiesel and diesel

\begin{tabular}{|c|c|c|c|}
\hline Fuel Property & Unit & Diesel & PME \\
\hline $\begin{array}{c}\text { Kinematic } \\
\text { viscosity at } \\
40^{\circ} \mathrm{C}\end{array}$ & $\mathrm{mm}^{2} / \mathrm{s}$ & 4.33 & 4.68 \\
\hline $\mathrm{CV}$ & $\mathrm{KJ} / \mathrm{kg}$ & 42418.48 & 34294.68 \\
\hline Flash point & ${ }^{\circ} \mathrm{C}$ & $52-82$ & 148 \\
\hline Ester content & $\%$ by mass & - & 97.8 \\
\hline Acid value & $\begin{array}{c}\mathrm{Mg}, \\
\mathrm{KOH} / \mathrm{g}, \\
\mathrm{max}\end{array}$ & - & 0.30 \\
\hline
\end{tabular}

Antimony tin oxide (ATO) was purchased from Sigma Aldrich manufacturer and used as additive. The properties of ATO were mentioned in Table.2.

Table-II: Specifications of nano particle

\begin{tabular}{|c|c|}
\hline Item & Specification \\
\hline Manufacturer & Sigma Aldrich, USA \\
\hline Chemical Name & Antimony Tin Oxide \\
\hline CAS No. & $<50 \mathrm{~nm}$ \\
\hline Particle Size & $47 \mathrm{~m}^{2} / \mathrm{g}$ \\
\hline Surface Area & Antimony Pentoxide, \\
\hline Composition & Tin (IV) Oxide, 89-93\% \\
\hline
\end{tabular}

\section{EXPERIMENTAL SETUP}

The experimental setup was showed in Fig. 3.

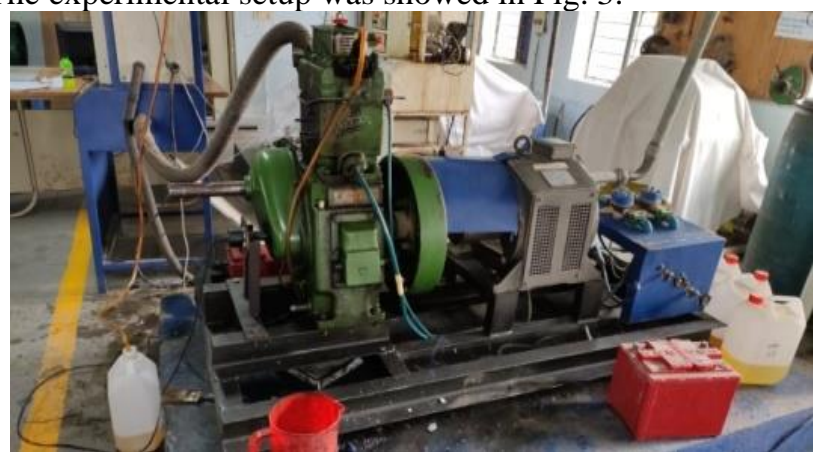

Fig. 3. Engine setup

Published By:

Blue Eyes Intelligence Engineering 
Exhaust gas analyser was used to measure CO, HC, NOx emissions. All fuel samples were prepared and $200 \mathrm{ppm}$ of ATO additive was used. The engine specifications were mentioned in Table.3.

Table-III: Specifications of engine

\begin{tabular}{|l|l|}
\hline Engine type & $\begin{array}{l}4 \text { Stroke computerized single } \\
\text { cylinder diesel engine }\end{array}$ \\
\hline Coolant & Water cooled engine \\
\hline Engine power & $5 \mathrm{HP}(3.7 \mathrm{KW})$ \\
\hline Bore diameter & $80 \mathrm{~mm}$ \\
\hline Stoke length & $110 \mathrm{~mm}$ \\
\hline Volume & $562 \mathrm{cc}$ \\
\hline Engine speed & $1500 \mathrm{rpm}$ \\
\hline
\end{tabular}

The engine was operated on diesel first and then on methyl esters of Palm oil and their blends with and without ATO additive. Series of tests were conducted with different blends on the engine and recorded the readings. The data obtained from the tests were then analyzed using graphs regarding performance and emission characteristics of all bio-diesels and diesel.

\section{IV.RESULTS AND DISCUSSION}

\subsection{Performance parameters}

\subsubsection{Brake power}

\section{i. Brake power without additive}

Figure 4.1 shows brake power variations with torque for diesel and PME blends at constant speed of the engine. Brake power (BP) has decreased with increase of PME blend percentage. As load increases, BP has also increased and at full load condition both diesel and biodiesel and diesel has highest brake power. In among all the blends of biodiesel, B10 has closest BP with diesel fuel when compared with biodiesel blends. The BP of B10 fuel is only decreased by $0.47 \%$ compared to diesel fuel.

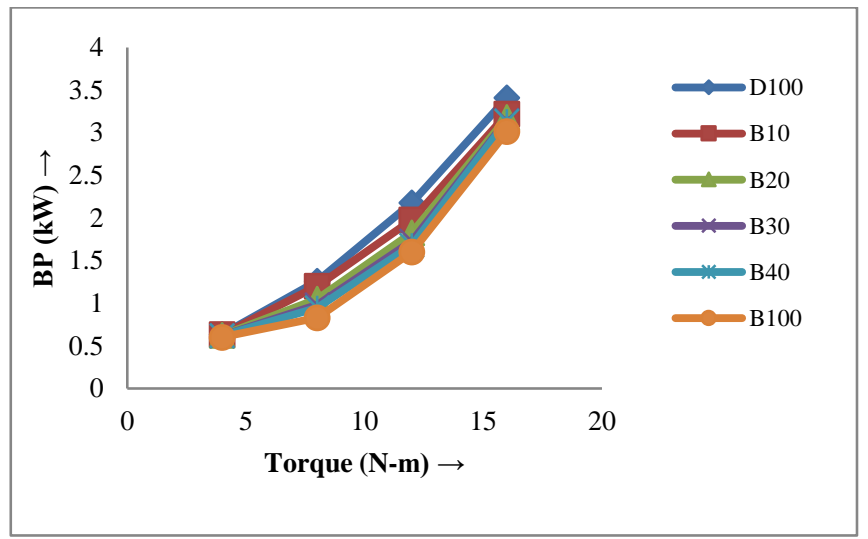

Fig.4.1 Brake power Vs Torque

\section{ii. Brake power with additive}

Figure 4.2 illustrates brake power variations with torque for diesel and PME blends with ATO additive at constant speed of the engine. Brake power (BP) has decreased with increase of PME blend percentage. With the addition of ATO, the BP of the engine for D100 fuel is increased by $0.628 \%$. But BP of the engine for B10ATO fuel is decreased by $0.78 \%$ compared to D100ATO. Other than B10ATO, the percentage decrease in BP compared with D100ATO is decreased for remaining blends. When additive is used, at low loads BP of the engine has increased but at high loads BP of the engine has decreased for the PME and its blends. BSFC has increased for all fuels when ATO nano particles used as additive.

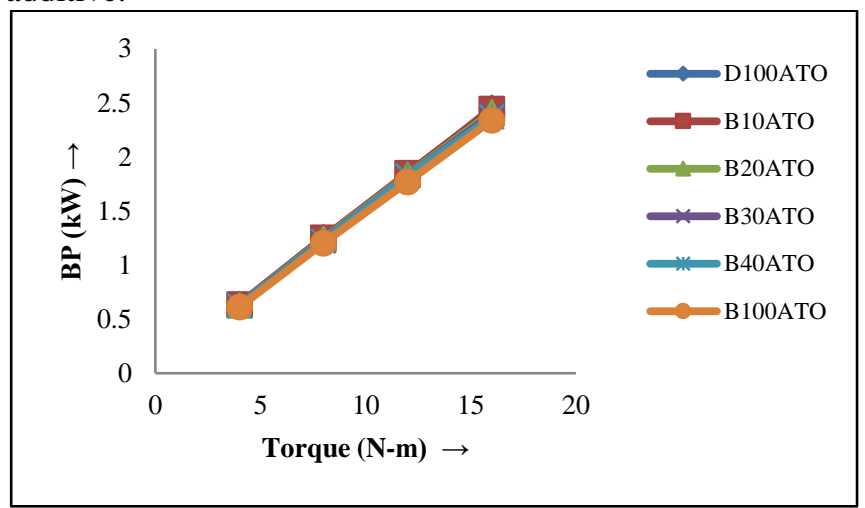

Fig.4.2 Brake power Vs Torque with additive

\subsubsection{Brake thermal efficiency}

\section{i. BTE without additive}

The Figure 4.3 shows the variation of brake thermal efficiency (BTE) with engine load for different palm oil biodiesel blends and diesel fuel. The diesel has highest BTE than all tested fuels and biodiesel in its neat form has the lowest BTE. The B10 has comparable BTE with diesel and has highest BTE when compared all biodiesel blends. The engine performance in terms of BTE has decreased by about $21.72 \%$ when neat biodiesel used in engine than that of diesel fuel due to lower calorific value of the biodiesel. The BTE has increased along with the increase of load for tested fuels and for every $10 \%$ addition of biodiesel content in the blend decreases the BTE at the rate of $2 \%$. The B10 blend was suitable replacement of diesel fuel in among all the tested fuels.

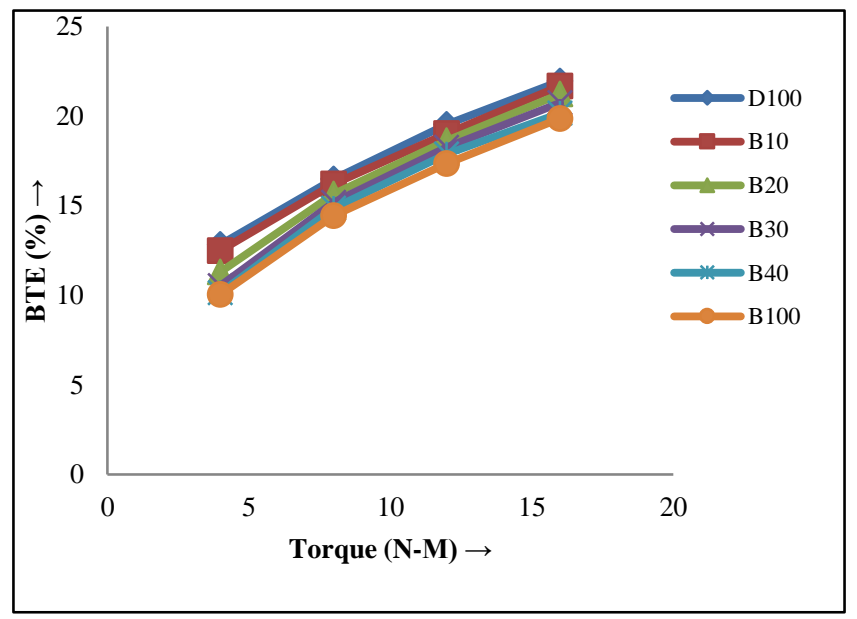

Fig.4.3 Brake thermal efficiency Vs Torque

\section{ii. BTE with additive}

Figure 4.4 shows brake thermal efficiency variations with load for diesel and PME blends with ATO additive at constant speed of the engine. The diesel has highest BTE than all tested fuels and biodiesel with ATO additive has the lowest BTE. 
The B10ATO has comparable BTE with diesel and has highest BTE when compared all biodiesel blends. The engine performance in terms of BTE has decreased by about $30 \%$ when biodiesel with ATO additive used in engine than that of diesel fuel with ATO additive. The B10 blend was suitable replacement of diesel fuel in among all the tested fuels.

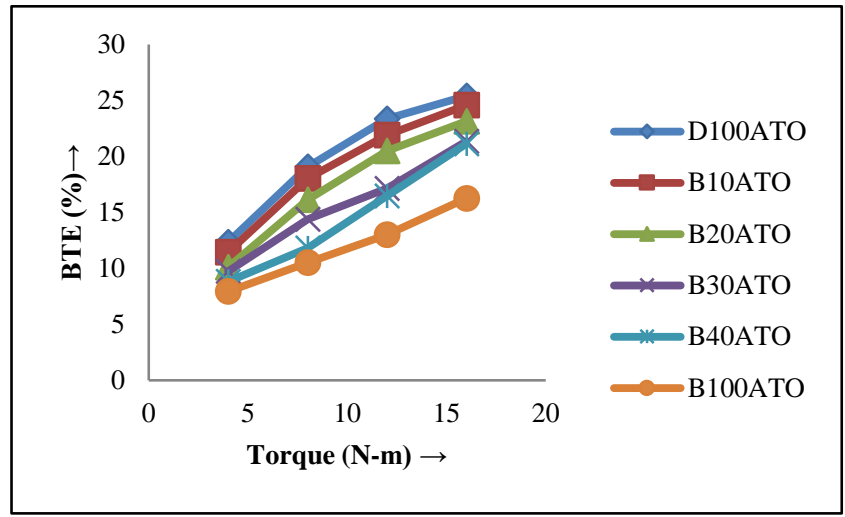

Fig.4.4 BTE Vs Torque with additive

\subsubsection{Brake Specific Fuel Consumption}

\section{i) BSFC without ATO}

The brake specific fuel consumption (BSFC) measure of the amount of fuel supplied to the engine to develop unit power. Figure 4.5 shows the variations of BSFC for all tested biodiesel blends with engine load. Diesel has lowest BSFC in all fuels and B10 showed lowest BSFC in among all the PME blends. As appeared in figure, BSFC expanded with increment of biodiesel mix rate. It is likewise seen that with increment of load, the SFC has diminished for both diesel and PME biodiesel. At part loads the expansion in SFC is higher yet as the load increases this value decreases and came to bring down at full load condition.

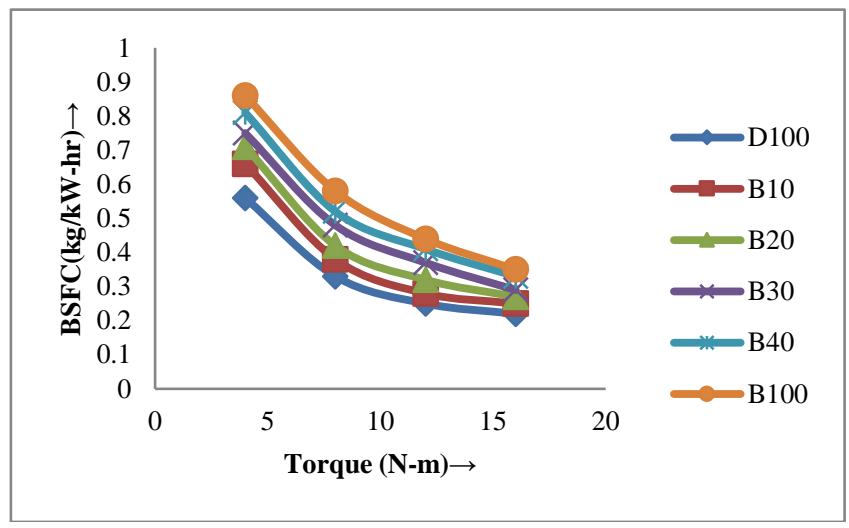

Fig.4.5 BSFC V/s Torque without additive

ii) BSFC with ATO

Figure 4.6 shows the variations of BSFC for all tested biodiesel blends with engine load. Diesel with ATO has lowest BSFC in all fuels and B10ATO showed lowest BSFC in among all the PME blends. As shown in figure, BSFC accumulated with increase of biodiesel mix proportion. It is also noticed that with increase of load, the specific fuel consumption has decreased for both diesel and PME biodiesel. At high loads the increase in specific fuel consumption is higher but as the load increases this value decreases and reached to lower at full load condition.

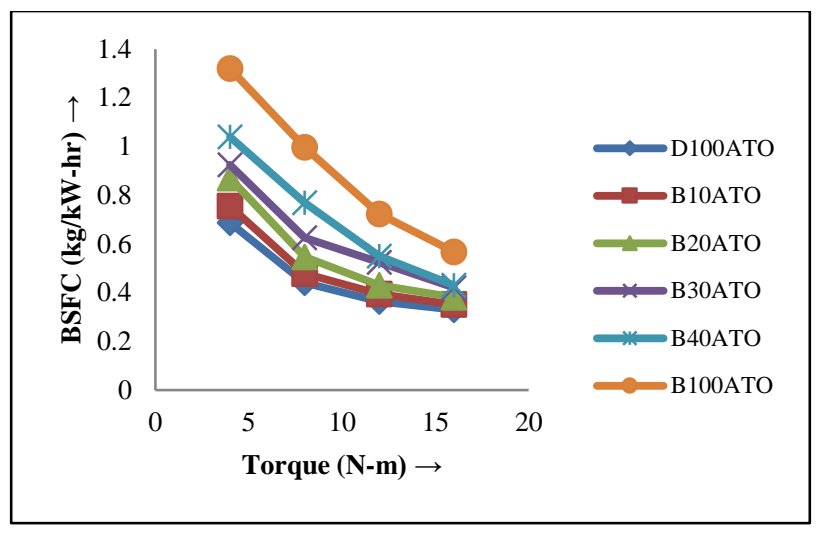

Fig 4.6 BSFC V/s Torque with additive

\subsubsection{Fuel Consumption}

i) Fuel consumption without additive

The mass flow rate of the fuel is calculated in $\mathrm{kg} / \mathrm{hr}$. The fuel consumption is more for the fuel B100 compare to remaining. At low loads the slope of the graph is less and it is more in between 5-10 N-m loads. As shown in Fig 4.7 B100 has high and D100 has low FC due to viscosity and other chemical properties. As load increases FC also increases for all tested fuels. B10 has near FC values compare to D100 at all loads because of B10 has similar properties as of D100.

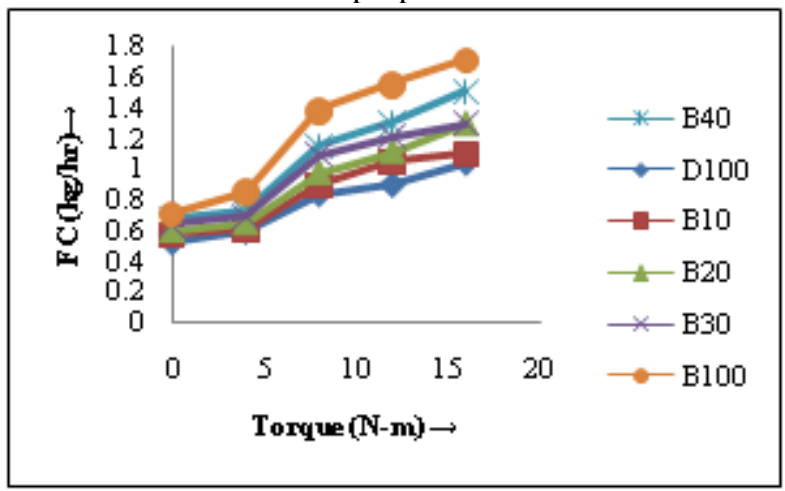

Fig.4.7 FC V/s Torque without additive

ii) Fuel consumption with additive

The mass flow rate of the fuel is calculated in $\mathrm{kg} / \mathrm{hr}$. The fuel consumption is decreased compare to fuel samples without additive D100, B10, B20, B30, B40, and B100. The slope for the fuel D100ATO is high and it is low for B100ATO. The variation is showed in the Fig 4.8.

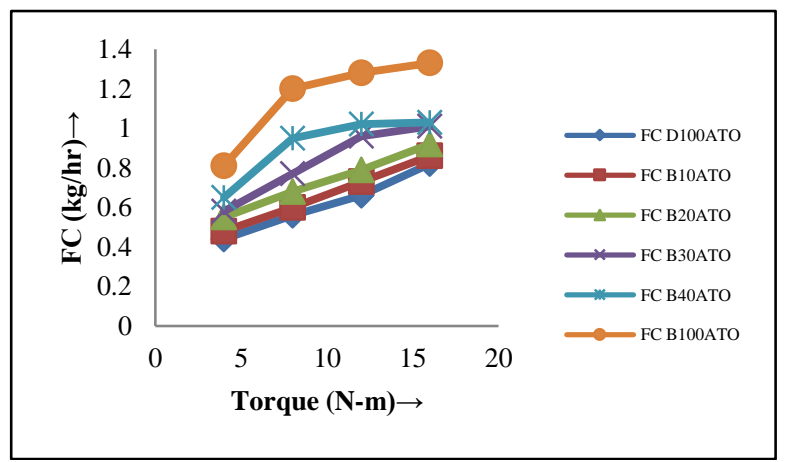

Fig.4.8 FC V/s Torque with additive 


\subsection{Emissions}

\subsubsection{CO emission}

\section{i) CO emission without additive}

The CO emission for D100 fuel is $0.03 \%$ and it is more than remaining fuels. As load increases CO emission also increases. The $\mathrm{CO}$ emission is increases as load increases. The biodiesel fueled engine emits less CO compared to the diesel and blends. Fig 4.9 demonstrates the variety of $\mathrm{CO}$ outflow at various loads on four stroke single chamber motor powered with biodiesel and its mixes. CO emanation is high when contrasted with biodiesel and its mixes of the motor. At high stacks CO discharge is diminishing somewhat in the event of $100 \%$ biodiesel. CI motors that work by and large lean for the most part have low CO emanations.

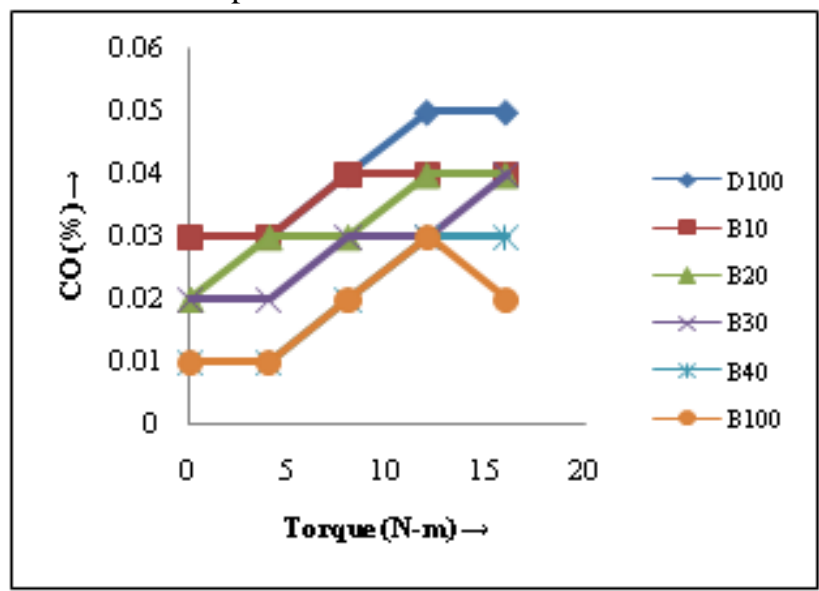

Fig 4.9: CO emission V/s Torque

ii) $\mathrm{CO}$ emission with additive

The fuel samples are D100ATO, B10ATO, B20ATO, B30ATO, B40ATO, and B100ATO without additive. The $\mathrm{CO}$ emission is increases as load increases. The biodiesel fueled engine emits less $\mathrm{CO}$ compared to the diesel and blends. Fig4.10 demonstrates the variety of CO outflow at various loads on four stroke single chamber motor powered with biodiesel and its mixes. CO emanation is high when contrasted with biodiesel and its mixes of the motor. The HC emission is high for diesel fuel and low for biodiesel. As load increases the $\mathrm{HC}$ emissions also increases.

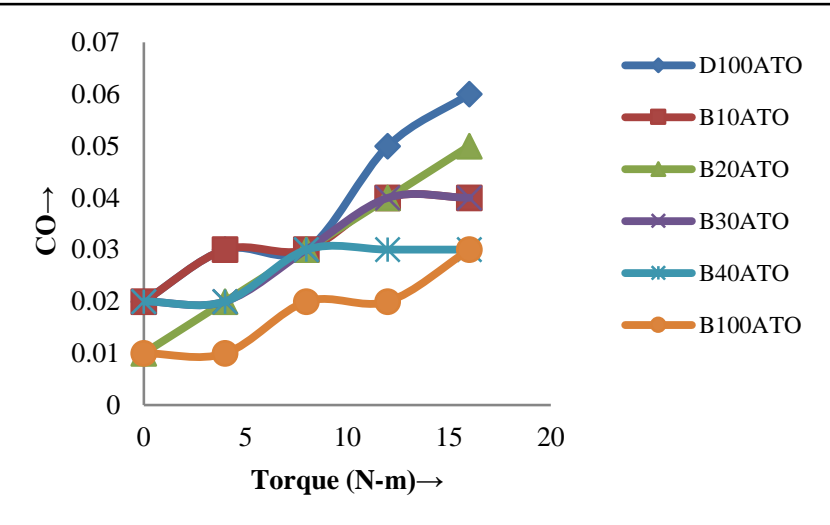

Fig.4.10 CO emission V/s Torque with addtive

\subsubsection{Hydro Carbons}

i) HC emission without additive

Figure 4.11 illustrates hydro carbons emission (HC) variations with load for diesel, PME blends at constant speed of the engine. It is seen that HC outflow is increasing with the increase in load for all fuels at the steady speed of the engine and diminishing with the increasing PME rate. At part-load conditions the variation of HC outflow of both biodiesel and diesel is indistinguishable, yet at medium and full burden conditions HC discharge of PME is distinct and diesel has higher qualities than PME and its mixes. The HC emanation has diminished by a normal of $70 \%$ of perfect PME biodiesel when compared with diesel and expanded by a normal of $10 \%$ for each $10 \%$ increase of PME in the mix.

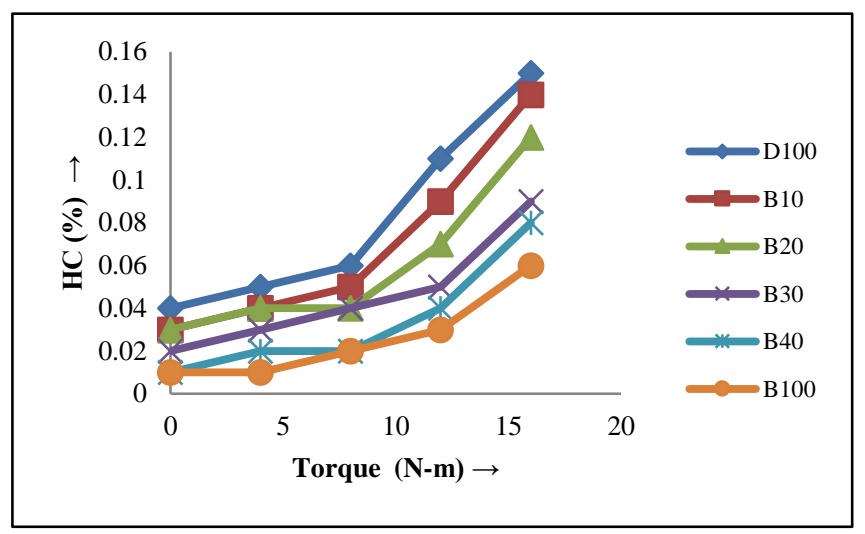

Fig.4.11 HC emission V/s Torque

ii)HC emission with additive

The values of HC are very less for pure biodiesel with ATO additive(B100ATO) compared with D100ATO. At no load condition the value is $0.01 \%$ for B100ATO. As percentage of biodiesel increases in the blends the value of $\mathrm{HC}$ emission is decreasing. Fig 4.12 shows the variation HC emission with respect to different loads. For all fuels as load increases HC emission also increases. But for the fuel B30ATO after $8 \mathrm{~N}-\mathrm{m}$ load decreased and at high loads again increased.

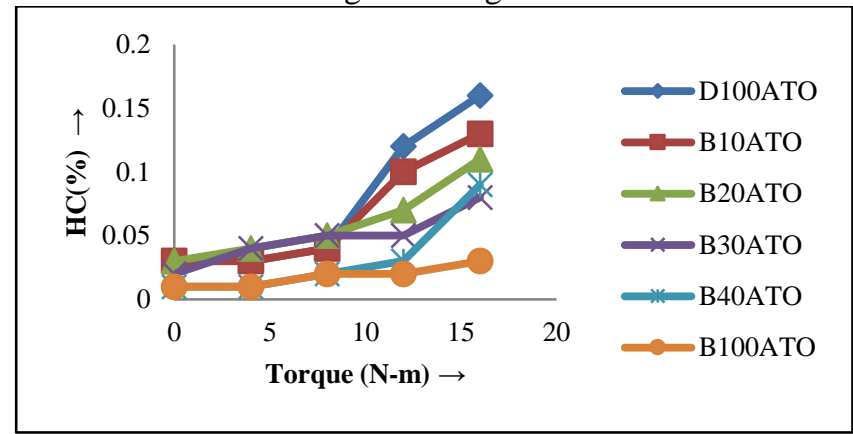

Fig.4.12 HC emission V/s Torque with additive

\subsubsection{Oxides of Nitrogen (NOx)}

i) NOx emission without additive

Figure 4.13 demonstrates NOx outflow variation with load for diesel, PME mixes at steady speed of the engine. It is seen that NOx discharge is increasing with the increase in load for all fuels at the steady speed of the engine and expanding with the expanding of PME rate.

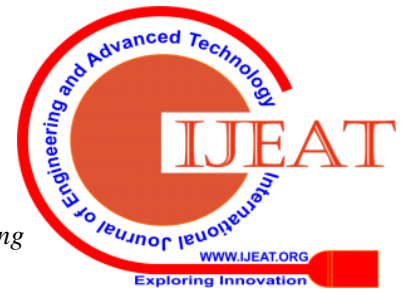


At part-load conditions the variation of NOx emanation of both biodiesel and diesel is unclear, yet at medium and full burden conditions NOx outflow of PME are particular and perfect PME has higher qualities than diesel and their mixes. The NOx emission has diminished by a normal of $31 \%$ of neat PME biodiesel when compared with diesel and expanded by a normal of $4 \%$ for each $10 \%$ expansion of PME in the mix at full burden condition.

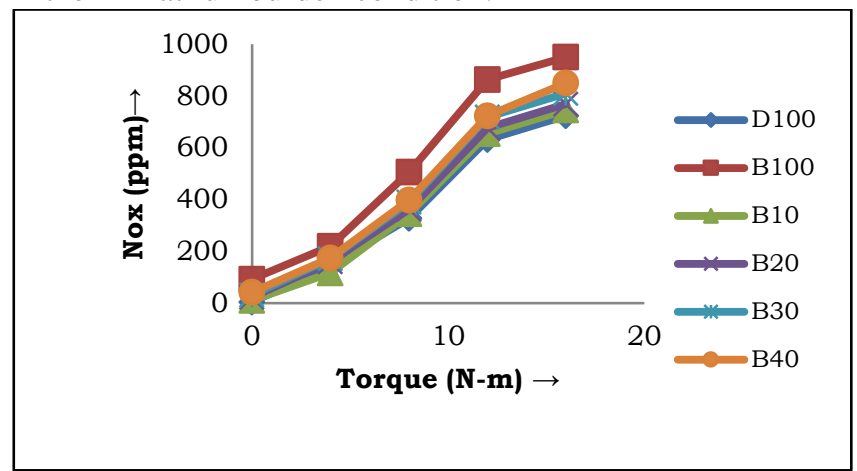

Fig.4.13 NOx emission V/s Torque

ii) NOx emission with additive

Figure 4.14 demonstrates NOx emission variation with load for diesel, PME blends at constant speed of the engine. The NOx values are more for the fuel D100ATO and less for the fuel B100ATO. At no load condition for fuel D100ATO NOx emission value is $9 \mathrm{ppm}$. At high load condition NOx emission for B100ATO is high 1012 ppm higher than D100ATO at high load. As load increases the values of NOx are increased. For the fuel B20ATO at $8 \mathrm{~N}$-m load slope decreased. At high loads for D100ATO emission is less compare to biodiesel and its blends.

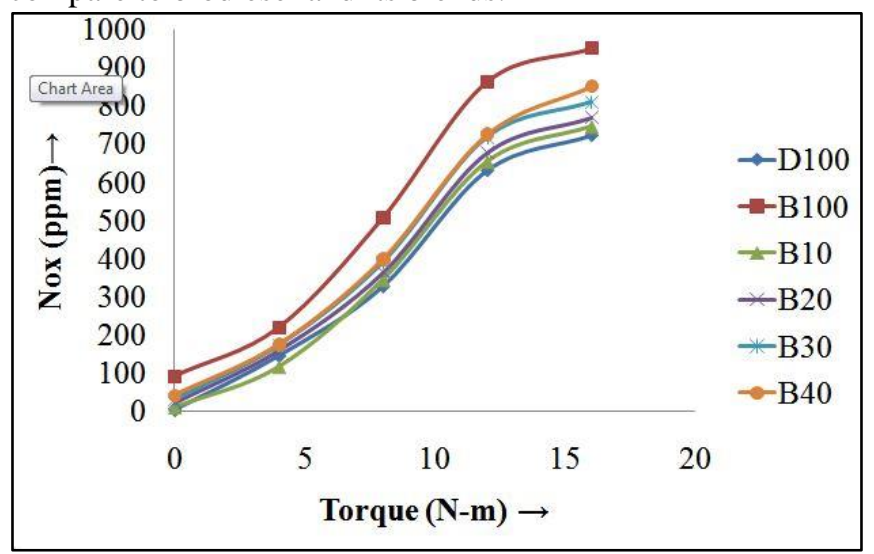

Fig.4.14 NOx emission V/s Torque with additive

\section{CONCLUSIONS}

The experimental investigation was carried out using a single cylinder, 4-stroke and water cooled diesel engine fuelled with Palm biodiesel blends and with ATO nano-particles as additives. From the trial results, the accompanying ends are drawn:

- The brake power was lower due to lower calorific values of biodiesel and its blends compare to diesel fuel.

- The biodiesel fuels provided similar brake thermal efficiency curves as diesel at low and medium engine loads when additive is used.

- As biodiesel proportion increases BSFC increases. However load increases BSFC decreased for all fuels.
- The biodiesel fuels produced less emissions than diesel under similar engine operating conditions, probably because palm oil contains oxygen which helps the combustion in the cylinder.

- The biodiesel produced more NOx emissions, especially at the higher engine load.

- $\quad$ BP of the engine at low loads has increased with the addition of ATO nano particles. However as load increases BP has been decreased compare to palm biodiesel and its blends.

- With the addition of ATO nano particles to the fuels BTE and BSFC increased.

- With the addition of ATO nano particles to the fuels CO emission decreased, HC emission is also decreased but NOx increased slightly.

Mixes of B-10 gives preferable outcomes over B-20, B-30, B-40, ATO added fuels because of

- It has similar properties compare to D100. CV of B10 is $41606 \mathrm{~kJ} / \mathrm{kg}$ and of D100 is $42418.48 \mathrm{~kJ} / \mathrm{kg}$.

- $\quad \mathrm{BP}$ of the engine for B10 is $0.633 \mathrm{~kW}$ and it is only 0.47 \% less compare to D100.

- $\quad$ BTE of the engine for B10 is $21.68 \%$ and for D100 it is $21.95 \%$.

- $\quad$ B10 has less CO and HC emissions compare to D100.

- It is less cost over B20, B30, B40, ATO added fuels

So it is prudent to use B10 as opposed to B-20, B-30, B40 in CI engine.

\section{ACKNOWLEDGEMENT}

The authors thank towards Guide, Principal and Executive Director of Sreenidhi Institute of Science \& Technology for providing necessary facilities to carry out this work in the institution.

\section{REFERENCES}

1. Sirivella Vijaya Bhaskar, "Experimental Analysis of DI Diesel Engine Performnace Fueled with jatropha Biodiesel”. ISSN:09755462, vol.9, No.02, 2017, Pages:60-65.

2. C. Syed Aalam, C.G. Saravanan, "Effects of nano metal oxide blended Mahua biodiesel on CRDI diesel engine", Volume 8, Issue 4, December 2017, Pages 689-696.

3. Ali M.A. Attia, Ahmed I. EL-Seesy, Hesham M. EL-Batsh, Mohamed S. Shehata, "Effects of alumina nanoparticles additives into jojoba alkyl ester-diesel mixture on diesel performance". IMECE2014-39988, Vol.8.

4. D.C. Rakopoulos, "Heat release analysis of combustion in heavy-duty turbocharged diesel engine operating on blends of diesel fuel with cottonseed or sunflower oils and their bio-diesel", Volume 96, June 2012, Pages 524-534.

5. Nagaraj Banapurmath, T. Narasimhalu, Anand Hunshyal, Radhakrishnan Sankaran, Mohammad Hussain Rabinal, Narasimhan Ayachit, Rohan Kittur, "Effect of silver nano-particle blended biodiesel and swirl onthe performance of diesel engine combustion", 10.11648/j.ijrse.20140306.15,2014.

6. Brian T. Fisher1 Jim S. Cowart Michael R. Weismiller et al. "Effects of Amorphous Ti-Al-B Nanopowder Additives on Combustion in an exceedingly Single-Cylinder Diesel Engine", 10.1115/1.4036189, 2017. 
7. V. Hariram, S. Seralathan, M. Rajasekaran, M. Dinesh Kumar and S. Padmanabhan, "Effect of Metallic Nano-additives on Combustion Performance and Emissions of DI CI Engine Fuelled with Palmkernel Methyl Ester", Hariram et al. 2017. Int. J. Vehicle Structures \& Systems, 9(2), 103-109.

8. Md. Rafsan Nahian, Md. Nurul Islam, Shaheen Mahmud Khan; Production of Palm Biodiesel and Performance Test with Diesel in CI Engine, 26-27 December,2016.

9. Gangadhara Rao, Kumar G N, Mervin Herbert, "Effects of Additives on Biodiesel/Diesel Performance, Emission Characteristics, Combustion Characteristics and Properties", ISSN: 2231-5381(2016).

10. Prabu Arockiasamy, Ramachandran Bhagavathiammal Anand, "Performance, Combustion and Emission Characteristics of a D.I. Diesel Engine Fuelled with Nanoparticle homogenized Jatropha Biodiesel". 10.3311/PPme.7766-2015.

11. Kurnia J.C., Jangam S.V., Akhtar S., Sasmito A.P., Mujumdar A.S. Prolysis advances in biofuel from oil palm and palm oil processing waste: a review. Biofuel Research Journal 9 (2016) 332-346.DOI:10.18331/BRJ2016.3.1.3

12. Jilin Lei, Yuhua Bi, and Lizhong Shen(2011), "Performance and Emission Characteristics of Diesel Engine Fueled with Ethanol-Diesel Blends in Different Altitude Regions". Volume 2011, Article ID 417421.

13. S. Ghosh, D Dutta. A comparative study of the performance \& emission characteristics of a diesel engine operated on soybean oil methyl ester (SOME), pangomia piñata methyl ester (PME) and diesel. ISSN 2319-183X. 1 (2012)22-27

14. Atul Dhar, Roblet Kevin and Avinash Kumar Agarwal (2012), "Production of Biodiesel from High-FFA nim tree Oil and its Performance, Emission and Combustion Characterization in an exceedingly Single Cylinder DICI Engine",

15. Rajesh. S, S V Prakash, Dinesh P, Girish V Kulkarni; CFD Analysis Of Biofuel (CNSL Blended With Diesel) Run Diesel Engine; IJRET; Eisen: 2319-1163; Volume: 05;PAGE:81-88.

\section{AUTHORS PROFILE}

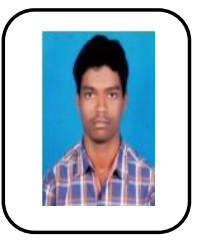

Kavide Shekhar has finished his Bachelor of Technology (B.Tech) in Mechanical Engineering from Anurag College of Engineering, Aushapur; by and by he is seeking after his Master's certificate (M.tech) in THERMAL ENGINEERING from Sreenidhi Institute of Science and Technology, Telangana. He finished his M.tech research work in a joint effort with regarded Professor Dr.S.VijayaBhaskar. Mail: kaviderajashekar1985@gmail.com

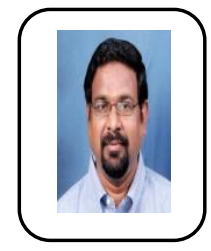

Dr. S. Vijaya Bhaskar has completed his Bachelor of Engineering (B.Tech) in Mechanical Engineering. He completed Master degree (M.Tech) in Machine Design, and also Ph.D's in study of ANN, Optimization Techniques, Alternative Fuels and management. Presently, he is a Professor of Mechanical Engineering at Sreenidhi Institute of Science \& Technology (SNIST) Hyderabad, Telangana. Mail: sbvijay@gmail.com 